\title{
POSTEMBRYOLOGICAL DEVELOPMENT OF SPIDERLINGS FROM TWO PERUVIAN LATRODECTUS POPULATIONS
}

\author{
By John D. McCrone, Florida Presbyterian College \\ AND \\ Her bert W. Levi, Harvard University
}

It is becoming increasingly clear that the solution of the complex taxonomic problems presented by the black widow genus Latrodectus will require more basic biological data than are now available. Of particular importance in this regard is information on the postembryological development of color pattern. Many Latrodectus populations show marked interpopulation differences in color pattern particularly of the immature stages. It is difficult to assess the taxonomic significance of these differences without reliable information on the development of these patterns in various populations.

Little such information has been published. The most extensive study was that done by Smithers (1944) with Latrodectus mactans indistinctus. He raised spiderlings from three different areas in South Africa and recorded the rate of development and the changes in color pattern after each molt. Unfortunately he confined his observations on color pattern to the females.

Recently we were able to obtain egg sacs from two different areas in Peru, Lima and Cuzco. We have reared 54 adults from these sacs and have recorded the changes in their color pattern after each molt. Morphologically these adults all appear to be Latrodectus mactans, probably the same as Latrodectus species "no. 3" of Abalos' cultures from Santiago del Estero Province in Argentina.

The spiders were raised in the laboratory in St. Petersburg, using a technique previously described (McCrone and Levi, 1964). A record was kept for each developing spider of the number of molts to maturity, the duration of the stadia, and the color pattern of each post-emergent instar. These data are presented in Table I and Figs. I-I9. The color patterns figured are the basic patterns found in each population. There were slight individual differences in pattern; however, these did not obscure the basic color patterns.

From the illustrations it can be seen that some instars are more polymorphic than others (Fig. 2, I5, I6) even though the adults end up with more or less similar patterns in females (Fig. 9, I8, 19),

\footnotetext{
*Manuscript received by the editor June 28, 1966.
} 


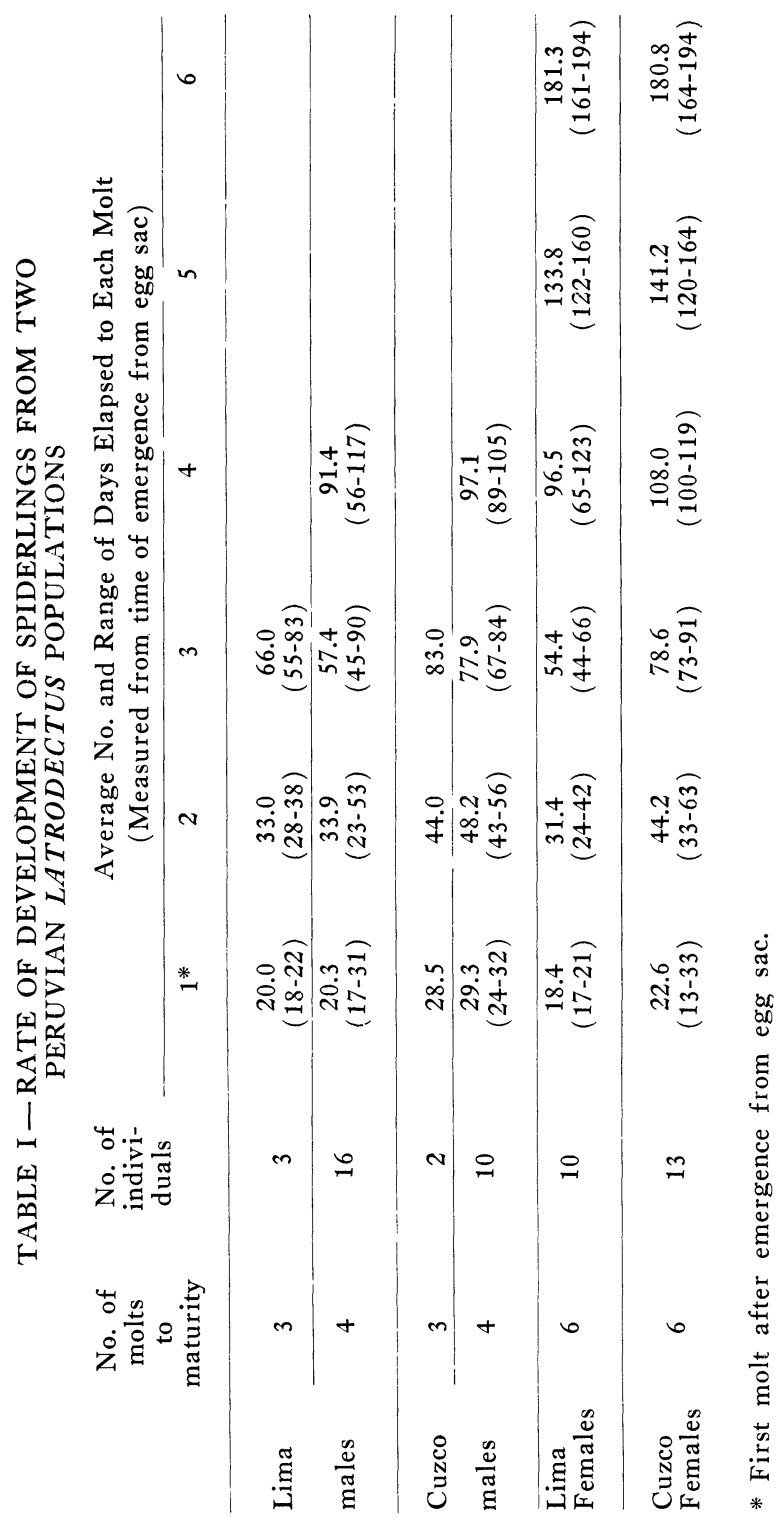


and quite different ones in males (Fig. 5, I3). The adult male is lighter than in the previous instar and the adult female is darker than in the penultimate stage. The individual variation of adult males is greater than that of adult females.

The spiderlings from Cuzco went through different color phases than did the Lima spiderlings although the adults are similar. Smithers ( 1944) reported the same phenomenon in South Africa. Adult females from the Little Karroo and Port Elizabeth were identical, but the color patterns of the immatures were quite different in the two groups. Considering the geographical proximity of the two Peruvian populations the differences in color pattern are remarkable.

Males from the Peruvian population were mated with $L$. mactans mactans from Florida. Although they readily mated and egg sacs were produced, none of the eggs hatched. Unmated Latrodectus do not produce an egg sac at all. Similar results were obtained when female L. mactans tredecimguttatus from Israel were mated with Florida L. mactans. The significance of this reproductive isolation is unclear because we have made no crosses with geographically intermediate populations. Members of different sympatric Florida species can not be mated with each other in the laboratory. The same observation has been made in Argentina (Abalos, pers. comm.).

The marked intra- and interpopulational differences in the color patterns of the immature and adult spiders from the two Peruvian populations studied show that the use of color pattern as a diagnostic species character must be done with great caution. For example, that some collections of juveniles from Texas were almost white, others black, seems to be of little significance. Both colorations were found after one molt (Fig. 2) from the same egg sac. Color pattern differences have significance only when they can be correlated with other morphological and biological characters (e.g. L. bishopi).

Explanation of Plate 10

Figures 1-9. Latrodectus mactans from Lima, Peru; coloration diagrammatic. Left venter, right dorsum with legs. Molts counted from after leaving egg-sac; there is one molt within egg-sac.

Fig. 1. After hatching (males and females). Fig. 2. After first molt (males and females); at right, variant pattern of about $10 \%$. Fig. 3. After second molt (males and females); at right, variant pattern. Fig. 4. After third molt (penultimate male). Fig. 5. After fourth molt (adult male). Fig. 6. After third molt (female). Fig. 7. After fourth molt (female). Fig. 8. After fifth molt (female). Fig. 9. After sixth molt (adult female).

White: white; crosshatch: light brown; double crosshatch: dark brown; light stipple: orange; dark stipple: red; black: black. There may be a yellow fringe around the red in areas marked white. 


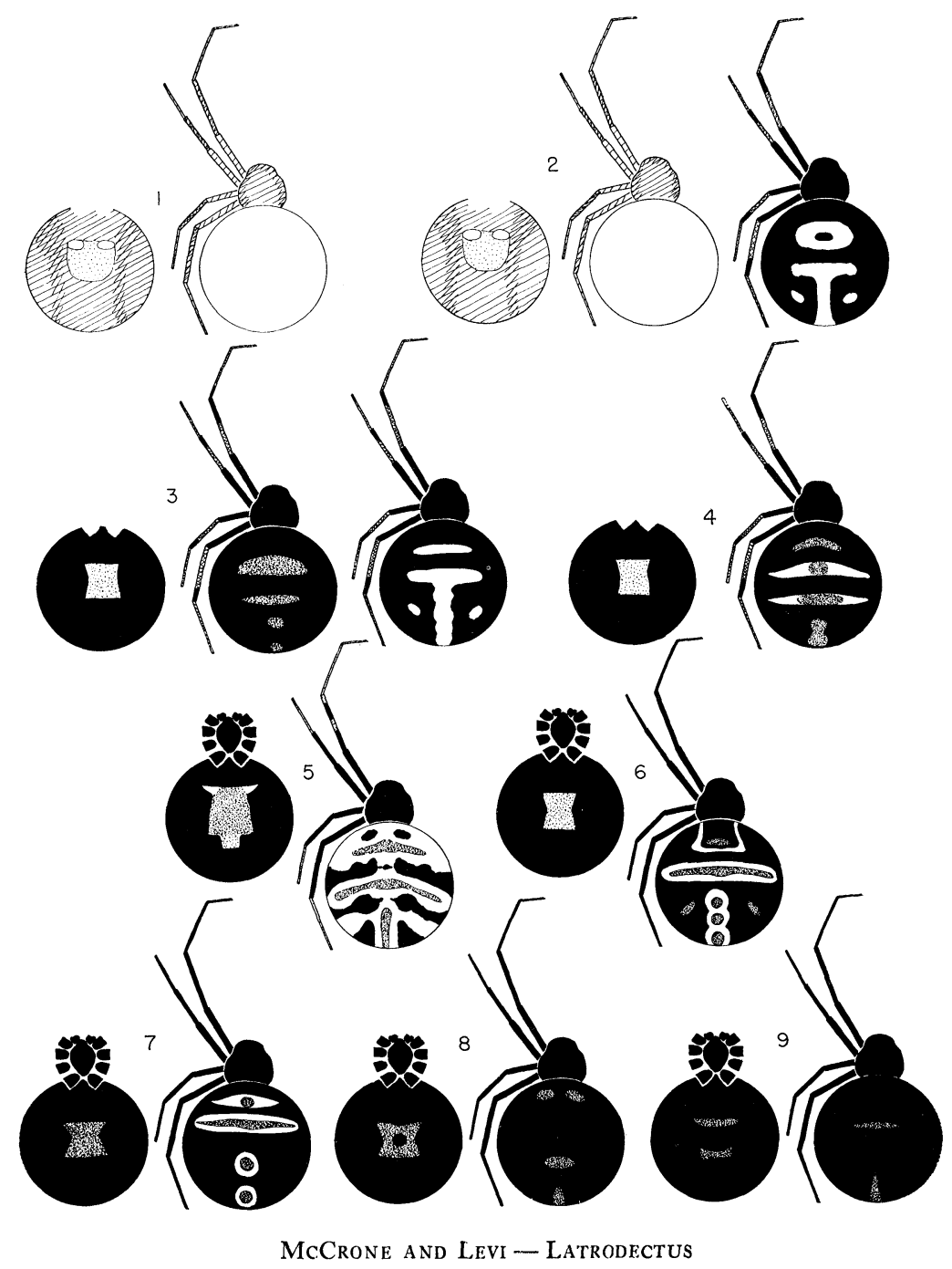


Another variable, not yet investigated, is the different number of molts to adulthood of females. While Turnbull (1960, 1965) found that different amounts of food do not change the number of molts in Linyphia triangularis (Linyphiidae) and Agelenopsis potteri (Agelenidae), it is known that the number of instars is variable in Nephila madagascarensis, examined by Bonnet (1930) and Gerhardt (1933), and in Latrodectus mactans, studied by Deevey (1949).

The spiderling molts once within the egg-sac. Herms et al. calculated that spiders remain between 14 and 30 days in the egg-sac; Lawson calculated a minimum of 15 days, but usually 3 to 4 weeks. Probably the temperature determines the length of this period. The second instar includes only the period after emergence. According to Herms, females from California molt 6 to 8 times, males 3 to 6. Blair reports that females from Alabama molt 6 times, males 5 . Lawson found that in Kansas females undergo 7 to 8 molts, males 4. Burt et al. reported 8 to 9 molts for Hawaiian females. Thorpe and Woodson recorded 6 to 9 molts for females and 3 to 6 for males. Deevey recorded that in southeastern Texas the females molt 7 to 9 times, the males 4 to 8 . Despite uniform conditions, in only one series did all the males and all the females from a single egg-sac mature at the same molt. All seven females fed maximally matured at the seventh molt. Deevey also recorded considerable variation in length of time to maturity. Latrodectus variolus and $L$. mactans may have been confused in some of these observations, although most probably apply to the much more common L. mactans. Unfortunately, it seems that none of the authors recorded differences in coloration of adults after different molts, although some poor photographs show change in patterns.

Deevey (1949), in a useful table, summarized the work of pre-

Explanation of Plate 11

Figures 10-19. Latrodectus mactans from Cuzco, Peru; coloration diagrammatic. Fig. 10. After hatching (males and females). Fig. 11. After first molt (males). Fig. 12. After second and third molts (male). Fig. 13. After fourth molt (adult male). Fig. 14. After third molt (female). Fig. 15. After fourth molt (female). Fig. 16. After fourth molt, variant coloration (female). Fig. 17. After fifth molt (female). Fig. 18. After sixth molt (mature female). Fig. 19. After sixth molt, variant pattern (mature female).

(Molts are counted from after leaving egg-sac; there is one molt within egg-sac.)

White: white; crosshatch: light brown; double crosshatch; dark brown; light stipple: orange; dark stipple: red; black: black. There may be a yellow fringe around the red in areas marked white. 


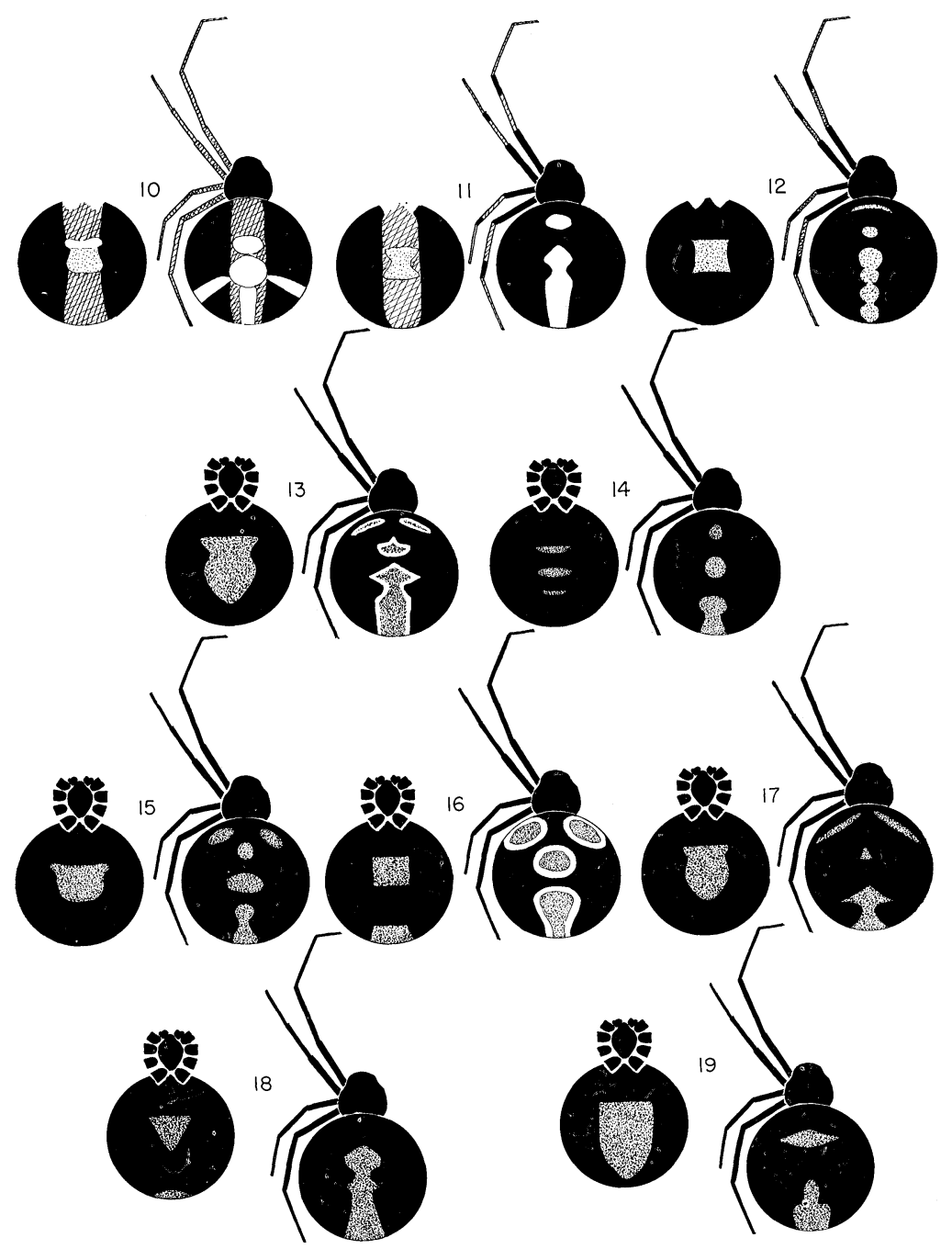

McCrone and Levi - Latrodectus 
vious authors, especially Bonnet, on the number of molts observed in spiders reared and the variation in number of instars. In addition, Deevey (1949) observed differences in color of eggs. Some eggs were pink, and out of them pink spiderlings hatched; most of the eggs were creamy white in color.

Acknowledgements: This investigation was supported in part by Public Health Service Research Grant AI-oI944 from the National Institute of Allergy and Infectious Diseases, and Public Health Service Research Grant GM I 206 from the National Institute of General Medical Sciences. We wish to thank Paul C. Dell for technical assistance and Dr. F. Carrasco Z. of the University of Cuzco for help in obtaining specimens from the area.

\section{Literature Cited}

Blair, A. W.

1934. Life history of Latrodectus mactans. Arch. Internal Med. 54:844850.

BONNET, P.

1930. Le Mue, l'autotomie et la régéne ration chez les Araignées. Bull. Soc. Hist. Natur. Toulouse 59: 237-700.

DeEvey, G. B.

1949. The developmental history of Latrodectus mactans at different rates of feeding. Amer. Midland Natur. 42: 189-219.

GerhardT, U.

1933. Neue Untersuchungen zur Sexualbiologie der Spinnen. Z. Morphol. Okol. Tiere 27: 1-75.

Herms, W. B., Bailey, S. F., and McIvor, B.

1935. The black widow spider. Bull. Calif. Agr. Exp. Sta. 591: 1-30. LAWSON, P. B.

1933. Notes on the life history of the hour-glass spider. Ann. Entomol. Soc. Amer. 26: 568-574.

McCrone, J. D. And Levi, H. W.

1964. North American widow spiders of the Latrodectus curacaviensis group (Araneae: Theridiidae). Psyche, 71: 12-27.

SMITHERS, R. H. N.

1944. Contribution to our knowledge of the genus Latrodectus in South Africa. Ann. South African Mus. 36: 263-312.

Thorp, R. W. ANd WoOdson, W. D.

1945. Black Widow, America's most poisonous spider. Univ. of North Carolina Press.

Turnbul., A. L.

1960. Prey of Linyphia triangularis. Canadian J. Zool. 38: 859-873.

1965. Prey abundance and the development of the spider Agelenopsis potteri. Canadian Entomol. 97: 141-147. 

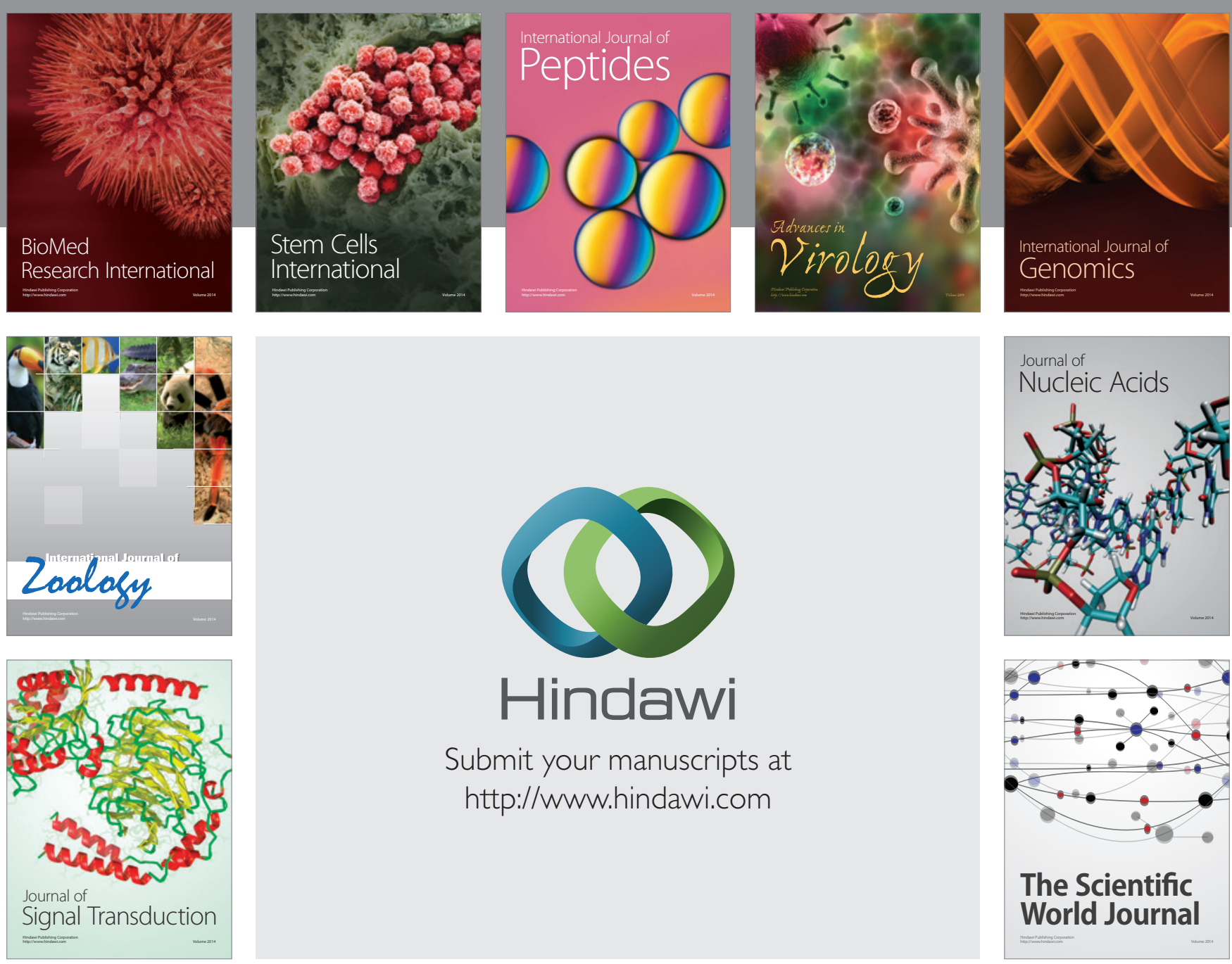

Submit your manuscripts at

http://www.hindawi.com
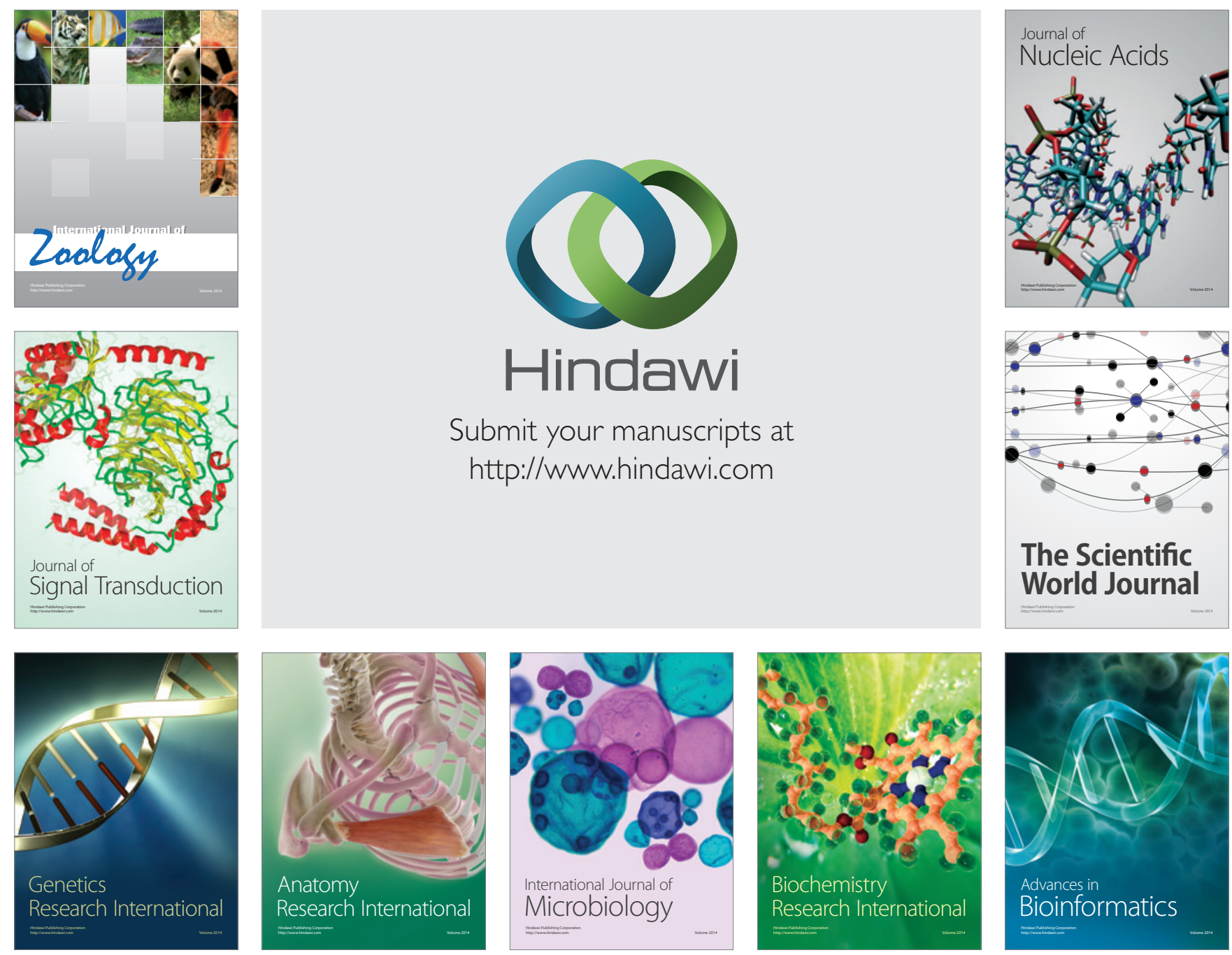

The Scientific World Journal
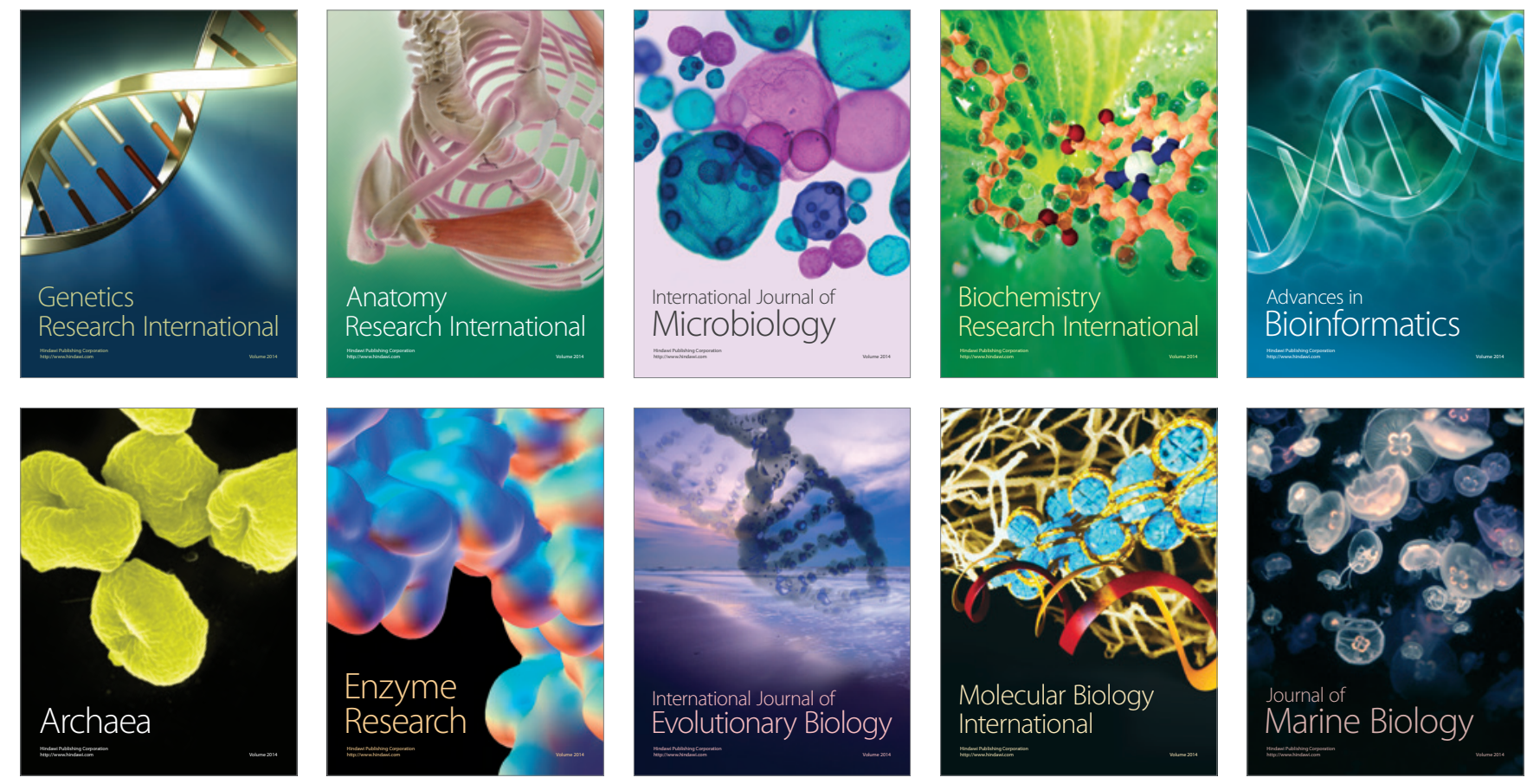